\title{
ESTRATEGIAS Y PROYECCIONES DEL SERVICIO AGRÍCOLA Y GANADERO EN APOYO A LA APICULTURA CHILENA.
}

\section{STRATEGIES AND PROJECTIONS FROM THE SERVICIO AGRÍCOLA Y GANADERO TO SUPPORT CHILEAN APICULTURE.}

Paula Cancino Viveros,

Encargada de Vigilancia y Sanidad Apícola, Subdepartamento de Vigilancia Epidemiológica, Servicio Agrícola y Ganadero, Chile.

Palabras clave: Estrategias, apicultura, Servicio Agrícola y Ganadero (SAG)

Introducción.

El SAG tiene como una de sus misiones, contribuir en la prevención o disminución de la probabilidad e impacto del ingreso, difusión y establecimiento de las enfermedades exóticas de las abejas. Del mismo modo el SAG procura apoyar el control o disminución de la morbilidad (prevalencia e incidencia) e impacto de las enfermedades endémicas. Estas dos misiones se realizan a través de las siguientes líneas de acción:

- Detección precoz.

- Respuesta emergencial.
- Control o erradicación de enfermedades endémicas.

Para las acciones antes mencionadas el SAG realiza una selección y priorización de las enfermedades exóticas y endémicas a intervenir. Realiza además, una evaluación costo beneficio, objetiva y transparente.

Este es un proceso dinámico, que se ajusta de acuerdo al riesgo-impacto que genera cada una de las enfermedades.

Estatus sanitario apícola nacional.

La situación de las principales enfermedades apícolas en Chile se entrega en el Cuadro 1:

Cuadro 1. Estatus sanitario según enfermedad y agente. (Abril 2007).

Table 1. Sanitary status according to disease and agent (April 2007)

\begin{tabular}{|c|c|c|}
\hline Enfermedad & Agente & Estatus \\
\hline Nosemosis & Nosema apis & Presencia señalada o conocida \\
\hline A cariosis & Acarapis woodi & Presencia señalada o conocida \\
\hline Varroosis & Varroa destructor & Presencia señalada o conocida \\
\hline Loque Europea & M ellissococcus pluton & $\begin{array}{l}\text { Enfermedad nunca constatada } \\
(*)\end{array}$ \\
\hline L oque A mericana & $\begin{array}{l}\text { Paenibacillus larvae } \\
\text { larvae }\end{array}$ & Presencia señalada o conocida \\
\hline Pequeño escarabajo & Aethina tumida & Enfermedad nunca constatada \\
\hline A cariosis & Tropilaelaps clareae & Enfermedad nunca constatada \\
\hline
\end{tabular}

(*): Nunca se ha aislado el agente causal, sin embargo, en la inspección clínica de colmenas algunos apicultores han observado signos compatibles con la enfermedad. 
Para este grupo de enfermedades, en general, el SAG realiza las siguientes acciones:

Diagnóstico oficial: tiene por objetivo poner a disposición diagnósticos, bajo estándares internacionales que den seguridad de diagnóstico de estas enfermedades.

Atención de denuncia: tiene por objetivo que, cualquier persona, en especial los productores, frente a cambios inesperados de la enfermedad puedan denunciar al SAG, se evalúe y se tomen las acciones correspondientes.

Estudios epidemiológicos: tienen como objetivo conocer la frecuencia, distribución y factores asociados a las enfermedades. Todo ello para facilitar la toma de decisiones sobre las acciones generales y específicas a realizar.

Acciones generales de control: tienen como objetivo evitar la introducción al país de la enfermedad, evitar la difusión y facilitar su control por parte de los productores. Ejemplos de ello son el registro y control de medicamentos, el control en barreras sanitarias, entre otros.

Acciones específicas de control: se refieren a aquellas que apuntan a identificar la enfermedad, disminuir su frecuencia en los apiarios o predios y a evitar su difusión a los apiarios o zonas que no tienen la enfermedad. Para ello se establece un conjunto de acciones coordinadas y ejecutadas por los diferentes actores. La decisión de realizar acciones de control o erradicación sobre una determinada enfermedad se toma sobre la base de una evaluación que justifique la participación del Estado en ello, considerando la importancia económica sobre el rubro productivo afectado, como a nivel país, el impacto que en salud pública pueda tener y la factibilidad técnica de la intervención.
Muestreo y vigilancia de enfermedades apícolas.

El muestreo y la vigilancia de enfermedades han buscado satisfacer la demanda de información objetiva que respalde la condición sanitaria de segmentos productivos específicos de la industria apícola.

La vigilancia de enfermedades se realiza durante el año calendario en todo el territorio nacional, y las enfermedades escogidas son determinadas basados en criterios tales como:

- La importancia clínico-económica, notificables a la OIE que tienen un potencial peligro de ingresar a nuestro país.

- Enfermedades que sean parte de convenios multilaterales, bilaterales o público-privados con fines de certificación.

- Enfermedades en las cuales, se observan cambios en los patrones de ocurrencia temporal y espacial, cambios en la exposición a factores de riesgo y enfermedades en que el desarrollo de nuevos sistemas de explotación, han ampliado la exposición de las poblaciones susceptibles.

También se realiza una evaluación del impacto sobre la industria y el comercio internacional, de las capacidades de diagnóstico de acuerdo a parámetros internacionales y se estiman los costos y recursos necesarios para su ejecución. Finalmente, con la realización de estas actividades, se procura mantener una vigilancia de enfermedades animales exóticas y prevalentes tal que permita verificar y respaldar la condición sanitaria de Chile y, disponer de la información necesaria para el apoyo en la toma de decisiones que involucren al rubro apícola. 